\title{
A prática da Consultoria na Dinâmica Informal do Polo de Confecções do Agreste Pernambucano
}

\author{
Amanda Lima VASCONCELOS \\ Universidade Federal de Pernambuco (UFPE), Caruaru, PE, Brasil
}

Ana Márcia Batista Almeida PEREIRA

Universidade Federal de Pernambuco (UFPE), Caruaru, PE, Brasil

\author{
Received 20 jan. 19; Accepted 22 jan. 19 \\ Evaluation System: Guest Article (Best paper of the 1st Scientific Conference on Administration [JCA] - UFPE / CAA) \\ Editor: Jose Lindenberg Julião Xavier Filho, Dr.
}

ISSN: 2594-8040

To cite this paper: Vasconcelos, A. L. \& Pereira, A. M. B. A. (2018). A prática de Consultoria na dinâmica informal do Polo de

Confecções do Agreste Pernambucano. Journal of Perspectives in Management - JPM, 2(2), p. 2-17.

\begin{abstract}
Resumo
O presente trabalho buscou caracterizar as fases de intervenção na ação dos consultores e as suas percepções sobre a informalidade na experiência socioprodutiva do Polo de Confecções do Agreste Pernambucano. Para atingir esse objetivo foi realizada uma investigação de caráter qualitativo utilizando entrevistas junto a consultores atuantes no segmento. Fez-se uso de um arcabouço teórico, contemplando a temática da consultoria e a história do Polo de Confecções, em sua dinâmica constitutiva e nas transformações recentes. Os resultados dessa pesquisa indicam que nas etapas de intervenção adotadas pelos consultores há variações entre as abordagens e adota-se uma sequência de fases lógicas que irão, a princípio, nortear a atuação desses agentes junto aos sistemas clientes, mas havendo abertura para ajustes à realidade das empresas. Quanto à informalidade, os consultores se depararam com empresas familiares imersas em formas de organização tradicionais, gestão intuitiva, ausência de planejamento, em paralelo com práticas referidas ao padrão formal, resultando no hibridismo entre o tradicional e o moderno.
\end{abstract}

Palavras-Chave: Consultoria, Informalidade, Polo de Confecções do Agreste Pernambucano. 


\section{Introdução}

A complexidade da economia e o crescimento dos mercados e da concorrência, associados ao avanço da Administração, produz cenários de incerteza. Nesse ambiente complexo, a necessidade de aquisição de conhecimento, adaptação e atualização torna-se vigorosa e acelerada, fazendo com que se busque o auxílio de consultores organizacionais (Cavalcanti \& Mattos, 2010; Crocco \& Gitmann, 2010; Loss, 2001). A Consultoria, segundo Schmidt Neto (2004), é uma atividade executada por uma pessoa ou equipe capacitada e independente à organização cliente, que influencia positivamente na produção de mudanças.

Verifica-se a ação das empresas de consultoria ou mesmo de consultores autônomos no Polo de Confecções do Agreste Pernambucano, especificamente, nos municípios de Santa Cruz do Capibaribe, Caruaru e Toritama, cuja atividade produtiva, de comércio e serviços é marcada pela alta incidência da informalidade, traduzindo-se numa gestão de caráter intuitivo, em formas improvisadas de organização dos processos, ambas permeadas por vínculos sociais e de parentesco. Porém, nas últimas duas décadas, vêm adquirindo uma configuração complexa, agregando essas características tradicionais a uma gestão racional em que se evidencia o uso de regras e normas, os vínculos formais de trabalho e a existência de princípios inerentes à estrutura burocrática ${ }^{1}$, aproximando-se da gestão moderna.

Nesse contexto, os serviços de consultoria se configuram como um novo instrumento de inserção junto a essa dinâmica (Oliveira, 2011; Lima, 2011; Pereira, 2011), em razão de atuarem na direção da modernização ao produzirem e disseminarem conceitos acerca do mundo empresarial (Donadone \& Sznelwar, 2004). Entretanto, a integração dessas práticas pelos consultores nos negócios locais torna-se desafiadora na medida em que resultados de pesquisas apontam a existência de uma relação tensa entre o moderno e o tradicional na dinâmica do Polo, engendrada na informalidade persistente nas formas de gestão e no trabalho (Pereira, 2018; Oliveira \& Braga, 2014; Oliveira, 2011; Lima, 2011; Bezerra, 2002).

Nesta linha de argumentação aberta pelos pesquisadores e adotando a perspectiva da informalidade imbricada à formalidade, apesar da polissemia que perpassa a noção, este artigo buscou caracterizar as fases de intervenção na ação dos consultores e as suas percepções sobre a informalidade na experiência socioprodutiva local. Deste modo, intenciona contribuir com o debate sobre a consultoria organizacional, colocando-a frente à frente com a dinâmica da informalidade no Polo de Confecções de Pernambuco, ao mesmo tempo em que se afasta do posicionamento de outros pesquisadores, que enfatizaram a consultoria na região associando-a ao tema da inovação e focalizaram a análise nos relatos dos sistemas clientes (Silva, Ribeiro, \& Silva, 2018).

Para atender a este propósito, o artigo está organizado para apresentar esta breve introdução; em seguida, a discussão teórico-bibliográfica focada no debate sobre consultoria organizacional e o Polo de confecções do Agreste, chamando atenção para a informalidade; na sequência, os capítulos de procedimentos metodológicos e discussão dos resultados e, ao final, as conclusões do estudo.

\section{Referencial Teórico}

2.1 Consultoria Organizacional: Origem e características do processo de intervenção em Micro e Pequenas Empresas (MPE)

O debate sobre consultoria está envolto numa polissemia que reflete a dispersão quanto ao seu significado (Moura, 2005), mas tem sido objeto de atenção por parte de estudiosos sob várias perspectivas. Jacintho (2004) usa a expressão "aconselhamento" para definir a consultoria, concomitantemente em que designa a mesma como um trabalho de diagnóstico no qual são identificados os problemas e indicadas propostas de melhorias ou correções, não necessitando a execução direta por parte do consultor. Apresentando um enfoque distinto a este, Schein $(1972$, p. 8) descreve a consultoria como "um conjunto de

\footnotetext{
1 Segundo Motta e Vasconcelos (2006), a estrutura burocrática é baseada na existência de funções definidas, competências determinadas por leis ou regulamentos, divisão de tarefas realizada racionalmente, deveres e direitos determinados por regras e regulamentos, hierarquia estabelecida por regras explícitas, recrutamento feito por regras estabelecidas previamente, remuneração igual para cargos e funções semelhantes, promoção e desenvolvimento de carreira sedimentados em critérios objetivos e normas, separação total entre a função e características pessoais do indivíduo.
} 
atividades desenvolvidas pelo consultor que ajudam o cliente a perceber, entender e agir sobre fatos interrelacionados que ocorrem no seu ambiente". Por outro lado, Oliveira $(2009$, p. 4) associa a consultoria à mudança, afirmando ser "um processo interativo de um agente de mudança externo à empresa, o qual assume a responsabilidade de auxiliar os executivos e profissionais da referida empresa nas tomadas de decisões". Tendo em vista o objetivo desta pesquisa, a consultoria será entendida como uma atividade executada por agente externo e independente ao sistema cliente, que dissemina conhecimento e influencia positivamente a produção de mudanças (Schmidt Neto, 2004).

A literatura contém registros da atividade associada às empresas de consultoria originadas a partir de fusões e aquisições, no final do século XIX e início do século XX, entre as décadas de 1850 e 1920 , destacando-se os países da Inglaterra e Estados Unidos como locais da sua gênese (Donadone, 2001). No que tange à atividade da consultoria organizacional, Feitosa e Pederneiras (2010) verificam que esta possui raízes no trabalho de eficiência operacional, no início do século XX, possuindo marcos importantes no período que sucedeu o final da Segunda Guerra Mundial. Crocco e Guttmann (2010) indicam que, após a Segunda Guerra Mundial, a percepção acerca da turbulência do ambiente cresce de forma drástica, levando as empresas a produzirem respostas a fim de resolverem suas necessidades.

A partir dos anos 1980, o campo da consultoria organizacional progrediu de modo crescente (Donadone, 2003), com destaque para a implementação de ferramentas gerenciais inspiradas nas ideias de gestão japonesa, a exemplo dos Círculos de Controle de Qualidade (CCQ's), do mercado de certificação sobre procedimentos de gestão e processos produtivos, representados essencialmente pelas normas da Organização Internacional de Padronização (ISO) (Donadone, \& Sznelwar, 2004). Mais à frente é dado enfoque aos pacotes gerenciais fundamentados na tecnologia da informação, buscando contemplar os numerosos setores presentes nas empresas (Donadone, \& Sznelwar, 2004).

Mesmo com este progresso, Wood Jr. e Caldas (2005) enfatizam que a indústria de consultoria apenas acelerou seu crescimento a partir da década de 1990. Neste momento, as grandes indústrias disseminaram e alicerçaram suas atividades em todo o mundo. Os processos de reengenharia das empresas colaboraram para a ampliação do espaço das consultorias nos meios empresariais e gerenciais, e dessa forma o setor ganhou destaque e importância. Nota-se isto no aumento das receitas que passaram de US\$22 milhões em 1990 para mais de US\$ 100 bilhões dez anos depois (Donadone \& Sznelwar, 2004; Donadone, 2003).

Nessa década, as empresas passaram a trabalhar substancialmente com o foco nas mudanças, empenhando-se em renovar seus métodos, técnicas e ferramentas, preenchendo essa demanda através da inovação (Crocco \& Gutmann, 2010). As empresas de consultoria no Brasil estiveram em evidência nos processos de privatização, fusões e aquisições e nos esforços de modernização gerencial que ocorreram após as reformas econômicas nos anos de 1990 (Feitosa \& Pederneiras, 2010). Donadone (2005) acrescenta que estas empresas ligadas à consultoria organizacional se destacaram como um dos setores mais dinâmicos do período. Entretanto, durante a década de noventa, muitas discussões a respeito dos modismos e gurus gerenciais aconteceram e passou-se a contestar a eficácia e os modos de atuação dos consultores. Dessa forma, começaram a surgir, sistematicamente, críticas à sequência de "fórmulas salvadoras de empresas" (Donadone \& Sznelwar, 2004).

Nos anos 2000, esse movimento tornou-se ameno e a indústria alcançou um patamar de maturidade e permaneceu influente na condução de processos de mudança organizacional e na difusão da ideologia do management. Nos últimos dez anos, verificando as práticas e estratégias de gestão de grandes grupos empresariais brasileiros é possível notar na raiz de suas práticas semelhanças com as ações de consultorias internacionais, tais como a McKinsey, Booz \& Company e a Pricewaterhouse Coopers (Feitosa, \& Pederneiras, 2010).

Vale salientar que não há uma generalização no contexto empresarial brasileiro no diz respeito a essas semelhanças, posto que é marcado pela predominância de MPE's que, por sua vez, apresentam 53,4\%, $22,5 \%, 36,3 \%$ de participação no PIB, nos setores do comércio, da indústria e dos serviços, respectivamente. Neste último, representa mais de um terço da produção nacional (SEBRAE, 2014; Santos, Krein \& Calixtre, 2012). Além disso, existe ainda um expressivo distanciamento entre estas empresas e os serviços de consultoria. No entanto, apesar desse cenário deve-se considerar que o crescente número de MPE's gera a necessidade pelos serviços de suporte à gestão, em função da complexidade do ambiente econômico que integram, dando espaço à consultoria, que surge como ferramenta de apoio à gestão, possibilitando acesso a 
profissionais dotados de vivências e conhecimentos (Miranda, Carvalho, Libonati \& Cavalcanti, 2013; Silveira, 2007; Teixeira, 2002).

Variados autores têm estudado o trabalho dos consultores, engendrando diferentes abordagens que retratam a atividade (Oliveira, 2005). Para Neves Jr. (2002, p. 1), o trabalho de consultoria é dividido em: "[...] investigação ou levantamento de informações, a identificação ou constatação de causas, o estudo de alternativas viáveis, a proposição de soluções e, em alguns casos, o acompanhamento e assessoramento na implementação das medidas recomendadas para solucionar os problemas existentes na organização" Neves Jr. (2002, p. 1). Block (2001) divide a consultoria em cinco fases: a "Entrada e Contrato", sendo o início do projeto com o cliente e engloba realizar a primeira reunião, investigar a natureza do problema, saber se o consultor é a pessoa certa para trabalhar o assunto e definir as expectativas de ambas as partes. Na "Coleta de dados e Diagnóstico" o consultor dispõe o seu ponto de vista sobre o problema auxiliando simultaneamente o cliente a fazer o mesmo. No "Feedback e Decisão de Agir", o consultor relata ao cliente a coleta e análise dos dados, executa o planejamento, estabelece metas finais para o projeto e define os passos de ação. $\mathrm{O}$ "Engajamento e Implementação" consiste em colocar em ação o planejamento realizado no passo anterior. $\mathrm{Na}$ "Extensão, Reciclagem ou Término" é realizada uma avaliação do que transcorreu no engajamento e implementação, podendo o projeto ser estendido a um segmento amplo da organização.

Semelhantemente ao exposto, Oliveira (2009) descreve o processo de consultoria em: "Identificação", fase em que se observa a situação da empresa-cliente. "Entrada", que consiste na realização do contrato de trabalho, definição das expectativas, compromissos, sistema-alvo e indagação dos problemas. "Auditoria de posição", momento de efetuar entrevistas, análises, estabelecer a situação e mudanças, reconhecer problemas, examinar causas, efeitos, pontos fortes e fracos. "Planejamento", etapa de estabelecimento das estratégias, responsabilidades, detalhamento das atividades, tempo e recursos. "Ação", que significa preparar o plano de trabalho, agir no sistema, treinar pessoas, institucionalizar mudanças. "Acompanhamento e avaliação", que é controlar resultados, avaliação pelo consultor e usuários, e caso necessário fazer nova auditoria de posição. "Conclusão", que se trata do desligamento do processo.

Em relação a estas abordagens referentes ao processo de consultoria, Jacintho (2004) observa que, de modo geral, as descrições assemelham-se muito, mas, de acordo com a formação do consultor, maior ênfase será atribuída à determinada etapa ou ferramenta no planejamento e na execução do processo. Associado a isso, o trabalho do consultor no ambiente das pequenas organizações normalmente é carregado de nuances que exigem desse profissional uma capacidade maior de adaptação, havendo a necessidade de preparo e atenção para atuar nesse tipo de empreendimento, pois os gestores possuem maior dificuldade para entender o campo de possibilidades das intervenções (Loss, 2001; Padula \& Valdon, 1996).

No Polo de Confecções do Agreste Pernambucano, os micro e pequenos empreendimentos predominam e tem sido evidenciada a atuação de consultores nessas unidades.

\subsection{O Polo de Confecções de Pernambuco: A experiência Socioprodutiva na região Agreste e a Persistência da Informalidade}

O recém-chamado Polo de Confecções do Agreste, situado entre a Zona da Mata e o Sertão de Pernambuco, firmou-se historicamente como um aglomerado de atividades produtivas, comerciais e de serviços, ao redor das Feiras da Sulanca ${ }^{2}$, nos municípios de Santa Cruz do Capibaribe, Caruaru e Toritama, estendendo-se, atualmente, por diversos munícipios do Agreste Pernambucano. As unidades produtivas são predominantemente compostas por "fabricos" e "facções" e as atividades comerciais acontecem nas feiras da sulanca e nos grandes centros comerciais (Oliveira, 2013, 2011).

\footnotetext{
${ }^{2}$ Feiras da Sulanca são feiras específicas de confecções na região Agreste de Pernambuco. O termo sulanca é uma corruptela resultante da junção de "Sul" e "Helanca", correspondendo ao tecido oriundo do Sul (São Paulo). A "sulanca" está associada à roupa popular vendida a preço baixo.

3 Denomina-se como fabrico as unidades produtivas familiares que funcionam comumente na base do trabalho domiciliar, de caráter informal. Podendo ter nenhum trabalhador contratado, utilizando-se unicamente mão de obra familiar, ou haver a contratação (geralmente informal). As facções são unidades produtivas formadas em condições ainda mais precárias que os fabricos, sendo subcontratadas por fabricos e fábricas para atender suas demandas, especializando-se na execução de uma ou mais tarefas do processo de produção: costura, bordado, corte, implantação de casas e botões, podendo ser composta por uma costureira ou por um grupo (Oliveira, 2013).
} 
Pode-se dizer que o "Polo de Confecções do Agreste nasceu pela ação do povo agrestino, que vislumbrou na produção de vestuário uma alternativa de renda para garantia da sobrevivência das famílias" (Zanatta, 2016, p. 136). Segundo Gomes (2002), a evolução desse território constituiu-se, gradativamente, em uma região sem tradição industrial e relações de trabalho baseadas no assalariamento, à margem da dinâmica propriamente capitalista, possuindo as feiras da sulanca como elemento de articulação socioeconômica.

Correlata à confecção, a produção da sulanca originou-se em Santa Cruz do Capibaribe, entre os anos de 1940 e 1950, a partir do deslocamento de comerciantes para Recife, no transporte de produtos, como queijo, carvão e galinhas, retornando e trazendo retalhos de tecidos, que a princípio eram usados para confeccionar colchas, tapetes, roupas de crianças e peças rústicas para o trabalho no campo, feitos pelas costureiras da região. Posteriormente, esses produtos foram vendidos nas feiras locais. Uma vez que a atividade se estabeleceu, gerando uma clientela, agregando produtores e vendedores, a demanda pelos retalhos aumentou e estes passaram a vir de São Paulo impulsionando a atividade. Desse modo, a feira da sulanca desenvolveu-se, no ano de 1970, em Santa Cruz do Capibaribe, em Caruaru, formou-se em 1980, e se estabeleceu em Toritama no final da década de 1990 (Gomes, 2002; Lira, 2006).

Através da iniciativa dos seus pioneiros, pouco tempo depois, surgiram diversas lojas atacadistas de tecidos e máquinas industriais de costura e aviamentos, auxiliando o fornecimento de insumos e a célere dilatação da produção (Lira, 2006). Com a ampliação das atividades produtivas e comerciais do aglomerado, as feiras da sulanca passaram a não comportar tal expansão e nos anos 2000, iniciava-se a construção dos grandes centros comerciais nas cidades-núcleo, resultantes da iniciativa de investidores privados, em parceria com os poderes públicos municipais.

Associado a isso, os primeiros passos direcionados à modernização do aglomerado remetem ao ano de 2002, em que por intermédio de instituições em conjunto com a liderança do SEBRAE e Sindicato das Indústrias do Vestuário do Estado de Pernambuco (SINDVEST) foi difundida uma forte campanha com o objetivo de renomear o aglomerado para "Polo de Confecções do Agreste de Pernambuco". Por meio de pactos de governança, incluindo a formação de um comitê gestor, reuniram-se consultores, representações empresariais, prefeituras, agências financeiras e gestores (Oliveira, 2013; Lima, 2011). Neste bojo, o Projeto "Sulanca Extra", que pretendia responder às demandas de capacitação dos confeccionistas de Santa Cruz do Capibaribe, gerou uma vasta campanha local na mídia e nas associações empresariais. Desse tempo em diante, foram empreendidos esforços em prol de uma reelaboração discursiva, buscando substituir a "Feira da Sulanca" por "Polo de Confecções"; o "Sulanqueiro" por "Empresário" (Lima, 2011; Oliveira, 2011).

Alguns anos depois, em 2009, foi divulgado pelo Estado o Programa de Produção e Difusão de Inovações para a Competitividade de Arranjos Produtivos Locais (PRO-APL), de Pernambuco, tendo o financiamento do Banco Interamericano de Desenvolvimento (BID), no valor de US\$2.606,07, e parceira com o SEBRAE-PE e a Federação da Indústria de Pernambuco (FIEPE), integrando parte das políticas públicas do Governo de Pernambuco, orientadas para o desenvolvimento da região (Pereira, 2018).

Pode-se afirmar que o destaque conquistado pelo Polo, nos últimos 10 anos, atribui-se conjuntamente à ação "de diversos agentes coletivos que passaram a atuar, tanto no sentido da criação de vínculos institucionais que denotassem a constituição de um Arranjo Produtivo Local, como em vista da resolução de problemas inerentes aos negócios locais" (Pereira, 2011, p. 173). Entre esses agentes, nota-se a atuação de consultores no aglomerado produtivo, quer sejam intermediados pelo SEBRAE, Serviço Nacional de Aprendizagem Industrial (SENAI), quer sejam de forma independente, configurando-se como um novo instrumento de inserção junto a essa dinâmica. Isso vem se dando, em um segmento de negócios marcado por: "[...] origem e comando familiar dos negócios; [...] prevalência de baixa escolaridade, pouca qualificação profissional; [...] baixa qualidade de grande parte da produção, preço competitivo e incrementos qualitativos recentes; a ausência de grandes plantas fabris [...] (Sá, 2015, p.197).

A respeito disso, Pereira (2013) explica que a indústria da região se desenvolveu sem estrutura e incentivos públicos, sobressaindo-se a autonomia dos empreendedores locais, investindo nas suas atividades tipicamente domésticas e familiares, sob uma visão, de início, mais artesanal. Assim, a informalidade marca a região do Polo de Confecções do Agreste e seus habitantes a usam para adentrar na produção, desenvolvendo suas atividades de modo improvisado, pois, até os dias de hoje, o Polo vive e se desenvolve em razão dos poucos impostos e direitos pagos, ignorando, na maioria das vezes, as obrigações trabalhistas. É expressivo o número de casos nos quais as famílias administram a venda de mercadorias, a compra e 
produção como um todo. Assim, observa-se que a forma de gestão e organização do trabalho se vincula ao parentesco e é conduzida de modo improvisado e intuitivo (Pereira, 2018; Lima \& Bezerra, 2002).

Nesses negócios, as unidades produtivas são estruturadas a partir de padrões similares de organização e processo produtivo, cujos proprietários "apresentam desconhecimento e dificuldades de assimilação de aspectos referentes ao gerenciamento da rotina, padronização e racionalização de seus empreendimentos" (Pereira, 2011, p. 126). Seguindo essa perspectiva, a articulação dos agentes coletivos em contato com o Polo para a adoção de práticas relacionadas ao padrão e à lógica moderna torna-se difícil tanto para trabalhadores quanto para os gestores, de modo que a integração de tais práticas aparenta ser algo custoso em função do desenvolvimento e da origem das atividades locais (Pereira \& Oliveira, 2013; Lima, 2011).

Essa dinâmica possui como marca a participação da informalidade no modo de gerir o negócio, observando-se a ausência de rotinas padronizadas, na qual, muitas vezes, utilizam-se anotações avulsas para o registro das entradas e saídas de mercadorias. Nesse cenário, as relações de trabalho obtêm um novo significado e a informalidade que sempre esteve presente, no desenvolvimento do Polo, passa a ser inserida não mais unicamente como estratégia para sobrevivência das atividades desenvolvidas ali, mas também como uma peculiaridade da recente dinâmica de acumulação estabelecida no seu núcleo (Bezerra, 2013; Pereira, 2018). Nesse sentido, Bezerra (2013, p. 335), afirma que "o Polo supera sua inserção local e 'marginal' na medida em que transforma seu sentido estrito de luta pela sobrevivência e adquire, para além desse, o sentido de estratégias de acumulação". Passando, então, a vigorar a acumulação de capital, norteada pela produção em larga escala, com o objetivo de produzir lucro, incorporando estratégias mais racionalizadas de gestão.

Nessas circunstâncias, "a modernização e a racionalização do processo produtivo e da administração dos empreendimentos não resultam, necessariamente, em abandono das antigas práticas, mas na combinação de velhas e novas práticas" (Zanatta, 2016, p.132). Sendo possível, as unidades produtivas possuírem uma fachada formal e permanecerem com suas operações na chamada "informalidade formal" (SEBRAE, 2013). Isto significa que apesar dos impulsos de formalização, o Polo não ultrapassou seu histórico de informalidade, que perdura, metamorfoseando-se (Oliveira \& Braga, 2014).

\section{Procedimentos Metodológicos}

A referente pesquisa é classificada como qualitativa respondendo a questões particulares, visto que busca caracterizar as fases de intervenção na ação dos consultores e as suas percepções sobre a informalidade na experiência socioprodutiva local, voltando-se, desse modo, para essa realidade social, em um nível que não pode ser quantificado (Minayo, 2009).

A investigação foi estruturada em quatro fases distintas: na primeira, realizou-se revisão de literatura, por meio da consulta a periódicos e livros sobre os temas de estudo. Na segunda fase, houve a delimitação do campo empírico, com o intuito de direcionar para o tema escolhido. Na terceira, ocorreu a seleção de 6 (seis) consultores, com base no critério da conveniência (Vergara, 2009), que concederam 5 (cinco) entrevistas semiestruturadas, no período de março a julho de 2018, cuja maioria ocorreu no ambiente de trabalho dos pesquisados, com tempo médio (individual) de 42 minutos, sendo devidamente gravadas, após autorização dos entrevistados, e transcritas na sequência. Na quarta e última fase, a análise do material de campo ocorreu inspirada nas recomendações de Minayo (2009), tendo início com uma pré-análise, seguida da exploração do material da entrevista, com foco nas (1) etapas de intervenção e (2) na informalidade local, finalizando com a interpretação, em diálogo com o debate teórico-bibliográfico sobre esses temas.

\section{Análise e Discussão dos Resultados}

\subsection{Fases de intervenção junto aos sistemas clientes}

A intervenção adotada pelos consultores se desenvolve, em geral, em meio a uma série de dificuldades quanto à adesão do sistema cliente durante as fases da intervenção, havendo nos relatos certo distanciamento entre o "discurso dos consultores quanto às recomendações propostas" e as situações concretas vivenciadas. Na ação junto às MPE's, como veremos, a problemática se torna ainda mais complexa diante das especificidades das formas de gestão e de trabalho na região (Pereira, 2018; Sá, 2015; Oliveira, 2013, 2011; Pereira, 2011). 
As etapas de intervenção são descritas pela consultora A, evidenciando-se a participação do gestor no sentido de adotar percepção mais intuitiva da situação problema e suas possíveis causas, conforme apresentado abaixo:

[...] toda empresa a gente inicia com um diagnóstico [...] "ah! eu sei mais ou menos os problemas da empresa" Eles relatam isso, mas não sabem as causas, o que causa, quais são as consequências [...] então muitas vezes, ele está vamos dizer, ainda sem muita noção do que acontece, ele acha que está sendo roubado e porque não tem controle e aí coloca uma pessoa da família no escritório e.. também não dá certo e por aí vai. Aí, eles têm uma certa noção vamos dizer, mas não tem a informação realmente completa pra identificar quais são as dificuldades da empresa [...] então a partir daí a gente mostra quais são os problemas da empresa a fundo mesmo [...] eles se sensibilizam mais com a questão dos resultados, se ele ver que: Ah! se eu melhorar nisso, eu vou ter uma rentabilidade melhor nesse aspecto [...] (Consultora A, entrevista em 26.03.18. Grifo nosso).

A partir do exposto, observa-se que no diagnóstico são levantadas informações sobre a situação da empresa cliente, ponto que vai ao encontro do definido por Neves Jr. (2002), que ao dividir o trabalho de consultoria, inicia esse processo a partir de uma investigação e constatação de causas. Também se percebe na intervenção a presença do acompanhamento das ações empreendidas e dos resultados, como caracterizado por Block (2001), na fase de extensão, reciclagem e término, na qual é avaliado o transcorrido nas fases antecedentes, havendo o controle dos resultados, conforme Oliveira (2009), através de uma avaliação realizada pelo consultor. Assemelha-se, nesse aspecto, à sintetização da consultoria descrita pelo consultor B:

A primeira fase é a fase de visita, a gente sempre visita [...] a lavanderia, visita e coleta dados, [...] então a gente de posse dos dados, coloca eles sobre a mesa e discute o que é que tá fazendo com que esses dados, eles revelem [...] tais resultados negativos para aquela empresa, [...] encontrando a causa do problema a gente pode propor a solução [...] Uma vez um cara ele chamou a gente para visitar a estação de tratamento dele e.. Ele falava que não tava conseguindo adequar o efluente dele a um parâmetro chamado DBO, a DBO mede como se fosse o nível de poluição [...] Então ele me chamou para estudar um processo produtivo dele pra ver o que estava causando esse excesso de DBO, então a gente elaborou um plano e eu fiz a intervenção, e ficou monitorando essa empresa, até hoje a gente monitora (Consultor B, entrevista em 16.05.18).

Essas abordagens acerca da consultoria refletem o constatado por Jacintho (2004) ao observar as semelhanças entre as fases, e a ênfase em etapas ou ferramentas condicionadas à formação do consultor. Para o consultor D, a consultoria é esquematizada da seguinte forma:

[...] por exemplo, há um mês, dois meses atrás, fomos em Santa Cruz, fechamos um contrato com uma empresa e.. eu não comecei pela metodologia normal que eu utilizo, fui diretamente pro financeiro, porque ela estava abrindo uma filial e queria confirmar se os preços que ela estava calculando, o preço era aliás da filial, da loja né da fábrica, aí se os preços estavam condizentes, se não estavam se é uma prática de mercado se não era, como era que calculava. Aí eu fui fazer algumas ações do financeiro pra poder e.. iniciar na parte estrutural do negócio né? Então muitas vezes acontece isso, mas há essa primeira reunião justamente pra definir o plano de ação (Consultor D, entrevista em 13.06.18).

A partir dessa descrição, também é interessante notar a flexibilidade da consultoria, que vai se adaptando conforme demanda a situação, permitindo personalizar as etapas segundo as características do sistema cliente, o que gera aproximação com a realidade local e suas necessidades. Essa perspectiva aparece também na abordagem do consultor F, quando indica a inexistência de um padrão que designe as fases da consultoria: 
[...] a primeira fase é o diagnóstico, o diagnóstico é fundamental, né? Você tem que ouvir o empresário, o que ele quer, né? $\mathbf{E}$ o que ele tem condição de fazer, porque às vezes chegam algumas demandas, aí diz assim: Ah o cara quer aumentar a produtividade, é muito fácil, todo mundo quer isso, quem é que tem uma empresa e não quer melhorar a sua produtividade? Agora às vezes as soluções são simples e às vezes não é tão simples, às vezes, na maioria das vezes requer investimento, aí você fala pro cara aí o cara diz: “Ah! Não tenho dinheiro não". Sim, aí como é que você quer aumentar a produtividade se você não disponibiliza o mínimo de recurso? Às vezes aquele aumento de produtividade requer algum investimento. Na maioria das vezes, requer, há necessidade e.. Então isso é tudo conversado com o empresário. [...] Em função dessa disponibilidade dele, se é feita a negociação, se definem as ações e se começa a execução [...] Às vezes, a consultoria ele mesmo, a gente finaliza a consultoria faltando alguma coisa, mas por parte deles. E eles: não eu reconheço que.. Quando... aí tem situações que o cara vai lá três meses ou quatro meses depois liga: "ó aquele negócio ali eu fiz visse, vem aqui!” Aí eu vou lá e faço e resolvo lá, entendeu? (Consultor F, entrevista em 02.07.18. Grifo nosso).

Identifica-se que nas abordagens apresentadas pelos consultores até o momento, basicamente o diagnóstico e as ações pós-diagnóstico ou implementação são recorrentes, constatadas também nas fases mencionadas pelo consultor E:

[...] Boa parte das indústrias de confecções hoje, se você for buscar fazer um trabalho de consultoria o que é que vai chamar atenção da empresa vai ser o aumento de produtividade, redução de custo. Então nas confecções por exemplo, isso é unânime em todas elas, o que que vai fazer o trabalho ser bom, ser aceito, ser desenvolvido ali é se você for levar uma metodologia com uma proposta que reduza custo, aumente produção, desenvolva a produtividade em processos específicos, então é muito parecido. [...] nem sempre boa parte deles tem algum controle de custos, né? A consultoria que acaba mostrando pra eles que os custos estão diferentes do que ele acha que está seguindo [...] (Consultor E, entrevista em 26.06.18).

Assim, nas etapas de intervenção junto aos sistemas clientes, percebe-se que apesar das variações das fases existentes de uma abordagem para a outra, não havendo em alguns casos uma padronização, e sim "criação" por parte dos consultores, nota-se que alguns consultores adotam uma sequência de fases, já conhecida, que inicialmente irá nortear sua atuação junto aos sistemas clientes. Neste processo, há espaço para ajustes à realidade das empresas, seguindo a racionalidade econômica no momento do gestor/contratante estabelecer os parâmetros para aferir os resultados da ação da consultoria, mas que se acopla à maneira intuitiva e não profissionalizada de gerenciar o negócio, sendo este um dos aspectos da informalidade presente na região.

\subsection{A percepção dos consultores em relação à informalidade}

No decorrer dos relatos dos consultores, foi possível identificar a percepção desses agentes em relação à forma de trabalho, à organização da empresa e às características específicas do segmento. Constatado nos depoimentos seguintes:

[...] Aqui a maioria das situações é o próprio dono que faz tudo, entendeu? Então não consegue acumular as atividades de planejamento, de programação por processos. São características bem específicas, empresas muito familiares que foram crescendo de uma forma desorganizada e aos poucos vão buscando organização [...] O pessoal aluga um galpão, monta no mesmo galpão um setor só e ali é o início, meio e fim do processo. $\mathrm{O}$ controle disso, claro, fica terrível (Consultor E, entrevista em 26.06.18).

[...] eles querem ter o controle na mão. Tem dono que vai, acende a luz pra começar o trabalho e só confia se ele desligar a luz no final do dia. [..] quer está em tudo, eles administram com os olhos, né? Então ele olha, e quer está em tudo que é canto. Aí não 
delega, no dia que ele falta, no dia que ele viaja, fica um caos. Exatamente por esse fato (Consultor F, entrevista em 02.07.18. Grifo nosso).

Os maiores problemas são, assim [...] porque, a maioria das empresas são familiares, aí não tem uma definição ou uma distribuição das atividades. Então, todo mundo faz tudo e ninguém faz nada, aí fica aquela confusão, então a maior dificuldade é essa (Consultor D, entrevista em 13.06.18).

Comparando-se os discursos dos consultores E, F, D, percebe-se algumas similaridades em relação aos sistemas clientes desse tipo de segmento: a ausência de delegação, formas improvisadas de organização das atividades, ausência de controle dos processos, empresas e gestão familiares. Na visão de Pereira (2013) e Pereira (2011) esses aspectos são produtos da forma com que a indústria da região se desenvolveu, partindo da iniciativa dos empreendedores locais que investiram em atividades situadas nos domicílios e núcleos familiares, conferindo a esses negócios padrões específicos de organização dos processos, com dificuldades em absorver aspectos de racionalização e padronização do gerenciamento. Convergindo com os relatos acima, identificamos alguns elementos indicativos da informalidade da gestão e dos processos, tais como: falta de profissionalização, ilegalidade, cultura de feira, visão de curto prazo, sendo salientados pela consultora A:

[...] temos a gestão da parte da confecção muito ainda informal aqui na cidade, então é muito informal ainda na região, na verdade porque nós atendemos Santa Cruz, Toritama e as cidades circunvizinhas, Surubim e a informalidade é muito grande e nossa empresa, como é uma empresa formal, a gente emite nota fiscal, por exemplo, aí as vezes eles não querem, e a gente entra na legalidade, mas eles são muito informais, muito ilegais e também falta profissionalismo, aí muitas vezes eles não querem fazer um trabalho ou começam e querem parar o trabalho de consultoria, porque vai mexer em várias questões da empresa, que muitas vezes eles não querem, querem só aquela questão de ganhar o dinheiro, mas não querem se organizar. O imediatismo, então é uma cultura local de feira, né? De ser imediatista, de produzir hoje para vender amanhã na feira e por aí vai. Mas não tem uma visão de longo prazo, de médio e longo prazo, então é aí que muitas empresas elas não têm tido uma sobrevivência e muitas vezes elas quebram [...] o empresário vai e abre outra com outro nome. É assim, a desorganização [...] não tem uma organização, [...] é bem primário mesmo, essa parte de gestão, então a gente tem que atuar. Muitas vezes a gente tem confeccionistas que mal sabem ler, entende? (Consultora A, entrevista em 26.03.18).

Nota-se que esses elementos influenciam no modo de produção dos sistemas clientes, que são reativos, produzindo conforme se vende; sendo esta prática corriqueira em micro e pequenos empreendimentos cuja justificação é a limitação de crédito e capital de giro. A gestão intuitiva é algo recorrente a ponto dos gestores não conseguirem identificar claramente as necessidades de seus negócios, requerendo sobremaneira a visão de um agente externo que analise a situação e traga uma percepção racionalizada das atividades ali desenvolvidas:

Quando eu apresento o projeto dizendo que o trabalho vai girar em torno desse desenvolvimento, a grande maioria diz: é exatamente isso que estou precisando, é exatamente isso que estou precisando, eles conseguem identificar que estão precisando de alguma coisa, mas não tem assim, digamos, um cronograma de ação, não tem uma lista das atividades; sabe que precisa, mas não tem uma coisa bem definida (Consultor $\mathrm{D}$, entrevista em 13.06.18).

Em decorrência da ausência de rotinas padronizadas (Bezerra, 2013), aliado à ausência de uma visão de longo prazo do negócio, o planejamento é inviabilizado resultando em perdas nos sistemas clientes, segundo indica a consultora A: "[...] eles fazem tudo em cima da hora, à medida que vai vendendo, vai e... vai vendendo, vai comprando e vai vivendo naquela roda viva, ai muitas vezes deixam de atender e de ganhar dinheiro de várias demandas" (Consultora A, entrevista em 26.03.18). A falta de planejamento não 
só ocorre dentro desses empreendimentos, manifesta-se no comportamento dos gestores em relação à consultoria, configurando nas situações descritas pelos consultores F e D:

[...] essa questão também desse agendamento, desse não planejamento, desse não cumprimento das obrigações que ele tem que fazer para que aquela consultoria funcione. [...] No caso de confecções mesmo, então o nosso consultor vai lá pra melhorar o processo aí diz: "olhe você tem que tirar essa máquina daqui e botar ali". Pra semana vai lá e está do mesmo jeito: "ah, o eletricista veio e não veio aqui". Aí na outra semana: "ah, o eletricista não veio e tal, ah, não sei o quê" (Consultor F, entrevista em 02.07.18. Grifo nosso).

Como se cria um calendário, aí marca no calendário, aí as vezes acontece de chegar. A visita é na quarta-feira de manhã, na terça-feira de manhã ele [o cliente] passa uma mensagem: "olha, amanhã não posso, não venha não que eu tenho um compromisso, que eu vou resolver coisa em tal lugar, não sei o quê. Dá pra você vir de tarde? Ou dá para vir em outro horário?" (Consultor D, entrevista em 13.06.18).

O discurso do consultor F vai ao encontro do previsto por Almeida (2007), quando identifica que nem sempre a visão de corresponsabilidade acerca do trabalho de consultoria é compreendida pelo cliente, em função do conhecimento pouco aprofundado sobre a natureza do trabalho do consultor, estando visível quando é relatado no depoimento o não cumprimento das obrigações no sistema cliente. Somando-se ao exposto, observa-se uma maneira de fazer informal, como coloca Pereira (2018), nesses sistemas clientes, como se apresenta nos relatos, que seguem:

Muitos processos trabalham na informalidade, por exemplo, ele fatura 100 mil reais por mês, para ocorrer aquele faturamento de 100 mil, aí ele precisa comprar um volume X de tecido, aviamento etc, para processar e depois vender para chegar naquele 100 mil. Aí o que muitas vezes acontece: ele compra 20 mil com nota fiscal e não identifica a parte que tem que vender com nota correspondente aquele $20 \mathrm{mil}$, fica trabalhando muito na informalidade, comprando e vendendo sem nota [...] aí muitas vezes ele faz pagamento na conta da pessoa jurídica pra pessoa física sem ter nenhum comprovante sem nada, aí eu pergunto se o contador não está fazendo a contabilidade da sua conta bancária. "Não, faz não, só faz da parte do que eu compro" (Consultor D, entrevista em 13.06.18).

[...] e muitas vezes ganham dinheiro, mas não, não contabilizam isso, não sabem quanto ganham nem quanto gastam, não tem a mínima noção de organização [...] na parte de confecção tem tido essas questões, né? Problemas realmente da falta de profissionalismo e a falta de formalização da empresa (Consultora A, entrevista em 26.03.18)

O descrito acima pelos consultores se conecta com as tendências relacionadas à dinâmica produtiva da região identificada por Sá (2015). No relatado pelo consultor D, nota-se que são utilizadas fontes próprias de conhecimento através da consultoria, nesse caso especificamente através do contador. Entretanto, esse conhecimento do negócio é limitado, pois o acompanhamento contábil não é realizado adequadamente. No segundo relato, percebe-se que os cálculos provavelmente são realizados de forma empírica, baseadas nas experiências do negócio, como citado por Sá (2015).

A forma de gerir o negócio presente na origem das atividades do Polo vem se reatualizando e se faz presente no desenrolar do trabalho de consultoria no sistema cliente ocorrendo uma dificuldade em relação ao que é proposto por esses agentes, sendo comum no decorrer da consultoria, o sistema cliente tornar a reproduzir as velhas práticas. Tal afirmação é identificada no relato do consultor D:

[...] na hora ali que se está definindo que se está conversando, que se está dialogando é muito fácil: "Ah! Então vamos lá [...]" Mas logo que começa a se desenvolver o trabalho, muitas vezes pelo fato de estar habituado a fazer daquela maneira, aí acontece muito de ficar incorrendo nos mesmos erros (Consultor D, entrevista em 13.06.18). 
Além disso, as características desse tipo de segmento influenciam o modo como o sistema cliente enxerga os serviços de consultoria, não sendo observados como investimentos (Alves, Dias \& Monsores, 2015), conforme expresso pelos consultores abaixo:

[...] a maior dificuldade é mostrar para a empresa que o custo da consultoria é um investimento, muitos encaram como despesa e ficam relutando então a maioria dos que eu prospecto, ou seja, que eu vou lá sem nenhuma indicação torna-se mais difícil de fechar contrato por conta disso, porque imagina como despesa (Consultor D, entrevista em 13.06.18).

Já teve empresário de falar que não quer gastar dinheiro com conversa fiada [...] ele vê a consultoria como uma coisa que é dispensável [..] Isso é uma grande dificuldade das empresas de consultoria aqui da região do Polo Têxtil, porque assim, a gente está lidando com empresários que não são acostumados com esse tipo de serviço [...] ele vê assim, no popular, uma atividade sem futuro [...] Ele não entende, por exemplo, que a atividade de um consultor é como se fosse a atividade de um médico, paga a consulta e paga o remédio ele enxerga do jeito diferente (Consultor B, entrevista em 16.05.18. Grifo nosso).

Tem uns (gestores) que reagem: "ah tá certo, bom, tudo bem, então eu sei que precisa, quando eu tiver condição eu faço". E às vezes, muitas vezes não é condição financeira às vezes é questão de prioridade (Consultor F, entrevista em 02.07.18).

Nota-se, a partir disso, que a consultoria ainda não é percebida como uma atividade necessária para que esses sistemas se desenvolvam. Associado a isso, percebe-se que a busca para os serviços de consultoria ocorre nas situações de urgência:

[...] muitas vezes só procuram um trabalho de consultoria quando estão perdendo dinheiro, já está bem agravante o problema [...] Eles percebem que não estão ganhando dinheiro, porque não estão trocando o carro todo ano, vamos dizer assim ou não estão fazendo a viagem que eles querem, porque não tem o dinheiro, aí eles procuram a consultoria quando a empresa já está em declínio e aí eles percebem de alguma forma: "não, eu quero saber o que está acontecendo na empresa" Aí vem fazer um trabalho de consultoria (Consultora A, entrevista em 26.03.18).

Configura-se, nesse caso, a situação proposta em Silva (2009), na qual o consultor é chamado quando a organização já está passando por uma situação grave. Outros fatores que propiciam a busca pelos serviços da consultoria são apresentados nos seguintes relatos:

[...] eles fazem todo um tratamento do efluente que é gerado na lavanderia [...] Quando esse tratamento é feito ele não chega nos limites preestabelecidos pelas legislações, então eles colocam tal problema, porque eu não consigo atingir a meta da legislação, então eu estou fora do parâmetro, então eu tenho que chegar nesse parâmetro se não vou ser autuado, vou ser multado ou coisa do tipo (Consultor C, entrevista em 16.05.18).

Já aconteceu caso de a gente ir na empresa e levantar aquela demanda e tal e tal e o cara ficar: "ah, depois eu vejo isso". Coincidente ou não, meses depois, foi lá um dos órgãos (fiscalizadores) desses daí e o cara foi multado e obrigado a fazer. Aí: [...] "vem aqui, pelo amor de Deus vai fechar minha empresa, tem que fazer" (Consultor F, entrevista em 02.07.18).

Nesses relatos, percebe-se que a busca desses sistemas clientes para os serviços de consultoria é resultado também das exigências de órgãos legais que fiscalizam as atividades procedidas, ou seja, não existe uma procura espontânea em função da escolha desses gestores em adotar um padrão formal, moderno. No relato do consultor $\mathrm{F}$, identifica-se que nem sempre essa procura significa a adesão dos serviços de 
consultoria pelo sistema cliente ocorrendo em casos extremos, quando esses gestores se deparam com uma imposição direta que ameaça a existência do seu empreendimento.

Contudo, é necessário enfatizar as mudanças percebidas pelo consultor $\mathrm{D}$, em relação à informalidade: "informalidade hoje diminuiu consideravelmente, mas ainda existe uma ramificação, digamos assim. Tem empresa de confecção que terceiriza alguns serviços com faç̧ões e não cobram das facções a regularização, aí ainda há alguns na ponta que estão na informalização (Consultor $\mathrm{D}$, entrevista em 13.06.18).

Nessa nova situação, é possível as unidades produtivas obterem uma fachada formal, permanecendo com suas operações na informalidade formal, como apresenta o SEBRAE (2013), considerando o descrito pelo consultor $\mathrm{D}$, no que se refere à diminuição da informalidade, acompanhada da persistência do trabalho subcontratado das facções, totalmente desprovido de proteção ou vínculo formal.

Portanto, em relação a percepção dos consultores frente à informalidade, identificam-se elementos típicos do contexto do Polo de Confecções do Agreste Pernambucano, tais como: formas de organização improvisadas, empresas familiares, gestão intuitiva, imediatismo nas tomadas de decisões, ausência de planejamento, que por sua vez, apontam diferenças quanto à gestão moderna.

\section{Considerações Finais}

Este artigo buscou caracterizar as fases de intervenção na ação dos consultores e as suas percepções sobre a informalidade na experiência socioprodutiva do Polo de Confecções do Agreste Pernambucano. Para tanto, o percurso teórico-bibliográfico recuperou estudos sistematizados sobre a origem da atividade de consultoria no país, suas conexões com o movimento da indústria de consultoria internacional e as principais etapas adotadas por consultores durante a intervenção nos sistemas clientes. Seguindo esta perspectiva histórica, remontamos a origem do aglomerado produtivo, comercial e de serviços no Agreste Pernambucano, cuja atividade de confecção teve como característica principal a produção em unidades de pequeno porte, no domicílio, com uso do trabalho familiar e predomínio da informalidade nas formas de gestão e do trabalho.

As mudanças nos últimos dez anos com vistas à formalidade dos negócios e do trabalho vêm conectando a experiência local à ação de consultores, visto que eles são um dos agentes difusores e implementadores de práticas de gestão modernas na região. Este aspecto justifica a realização desta pesquisa principalmente atrelada à persistência da informalidade, que torna complexa a atuação dos consultores nos empreendimentos locais. Neste estudo, a perspectiva teórica adotada sobre a informalidade considerou o imbricamento entre o formal e o informal abandonando as chaves dualistas e o entendimento da informalidade como anomalia ou questão espúria.

Após realização de entrevistas junto a consultores com experiência em sistemas clientes do segmento de confecções na região, evidenciou-se que nas etapas de intervenção adotadas pelos consultores pesquisados há variações de uma abordagem para a outra, no que diz respeito ao número de etapas e modos de execução, não existindo em alguns casos uma padronização. Percebe-se que alguns consultores adotam uma sequência de fases previsíveis, havendo inicialmente o diagnóstico, as ações pós-diagnóstico ou implementação e por fim o acompanhamento. Estas fases irão, a princípio, nortear a sua atuação, podendo, posteriormente haver um ajuste à realidade das empresas, situação que ocorre em função das dificuldades enfrentadas pelos consultores na adesão dos gerentes/contratantes às recomendações propostas. Nesse sentido, constatou-se que os consultores atuam essencialmente a partir da adaptação, utilizando-se desta como um meio de inserção nos sistemas clientes.

Em relação à percepção dos consultores sobre a informalidade, os relatos indicaram formas de organização improvisadas, centralidade das empresas familiares, gestão intuitiva, imediatismo e ausência de planejamento, que expressam divergências em relação à gestão moderna. No entanto, em se tratando da venda de um "pacote gerencial", a informalidade abre uma oportunidade para a atuação dos consultores na região, principalmente nos sistemas clientes onde já se percebem mudanças na adoção de práticas pertencentes ao padrão formal ou mesmo quando esse agente percebe as fortes conexões da informalidade com o padrão dominante de gestão e de trabalho. 
Para pesquisas futuras, sugere-se que seja ampliado o número dos consultores com vistas ao aprofundamento da análise, além de realizado um estudo bilateral do fenômeno, aumentando o alcance da pesquisa e incluindo os gestores das unidades produtivas da região.

\section{Referências}

Almeida, A. M. B. (2007). A construção da confiança na relação entre os consultores organizacionais $e$ clientes: uma compreensão baseada no conhecimento da vida cotidiana e na prática reflexiva. Dissertação de mestrado, Universidade Federal de Pernambuco (UFPE), Programa de Pós-graduação em Administração (PROPAD), Recife, PE, Brasil.

Alves, J. D. C., Dias, N. T., \& Monsores, G. L. (2015). Consultoria empresarial como ferramenta estratégica de desenvolvimento em pequenas empresas. Anais do XII Simpósio de excelência em gestão e tecnologiaSEGeT, Rezende, RJ, Brasil, 12.

Bezerra, E. (2013). O trabalho das mulheres na origem e desenvolvimento do Polo de Confecções do Agreste de Pernambuco. In Oliveira, R. V., \& Santana, M. A. (Org.). Trabalho em territórios produtivos reconfigurados no Brasil. João Pessoa: Editora da UFPB.

Block, P. (2001). Consultoria: o desafio da liberdade. São Paulo: Makron Books.

Cavalcanti, I. T., \& Mattos, P. L. C. L. (2010). Legitimação profissional: fatores e estratégias que acompanham as relações dos consultores organizacionais com os seus clientes. In Feitosa, M. G. G.; \& Pederneiras, M. (Orgs.). Consultoria Organizacional: teorias e práticas. São Paulo: Atlas.

Crocco, L., \& Guttmann, E. (2010). Consultoria empresarial (2a ed.). São Paulo: Saraiva.

Donadone, J. C. (2001). "Os hunos já chegaram”: dinâmica organizacional, difusão de conceitos gerenciais $e$ a atuação das consultorias. Tese de doutorado, Escola Politécnica da Universidade de São Paulo, São Paulo, Brasil.

Donadone, J. C. (2003). O mercado internacional de consultorias nas últimas décadas: crescimento, diversificação e formas de disputa. Caderno de Pesquisas em Administração, 10 (2), 1-15.

Donadone, J. C. (2005). A difusão de conceitos gerenciais, imprensa de negócios e o mercado de consultoria no anos 90. Revista Eletrônica de Gestão Organizacional, 3(1), 26-38.

Donadone, J. C., \& Sznelwar, L. I. (2004). Dinâmica organizacional, crescimento das consultorias e mudanças nos conteúdos gerenciais nos anos 90. Revista Produção, 14(2), 58-69.

Feitosa, M. G. G., \& Pederneiras, M. (Orgs.). (2010). Consultoria organizacional: teorias e práticas. São Paulo: Atlas.

Gomes, S. C. (2002). Do comércio à feira da sulanca: uma inserção de migrantes em São Paulo. Dissertação de mestrado, Faculdade de Filosofia, Letras e Ciências Humanas, Universidade de São Paulo (USP), São Paulo, Brasil.

Jacintho, P. R. B. (2004). Consultoria empresarial: procedimentos para aplicação em micro e pequenas empresas. Dissertação de mestrado, Universidade Federal de Santa Catarina (UFCG), Florianópolis, SC, Brasil.

Lima, A. S. (2011). "Empreendendo" a Sulanca: o Sebrae e o Polo de Confecções do Agreste de Pernambuco. Dissertação de mestrado, Universidade Federal de Campina Grande (UFCG), Campina Grande, PB, Brasil.

Lira, S. M. (2006). Os aglomerados de micro e pequenas empresas de confecções do Agreste/PE: um espaço construído na luta pela sobrevivência. Revista de Geografia, 23(1), 98-114.

Loss, C. F. (2001). Consultoria empresarial em pequenas e médias empresas: um estudo das relações entre consultoria versus empresa em Chapecó/SC. Dissertação de mestrado, Universidade Federal de Santa Catarina, Florianópolis, SC, Brasil.

Minayo, M. C. S., Deslandes, S. F., \& Gomes, R. (2009). Pesquisa social: teoria, método e criatividade (28a ed.). Rio de Janeiro: Vozes. 
Miranda, L. C., Carvalho, I. R., Libonati, J. J., \& Cavalcanti, P. R. N. (2013). Práticas de contabilidade gerencial: evidências em consultorias oferecidas por revistas especializadas aos empresários das micro, pequenas e medias empresas. Revista de Contabilidade e Controladoria, 5 (1), 139-15.

Motta, F. C. P., \& Vasconcelos, I. G. (2006). Teoria geral da administração. São Paulo: Thomson Learning

Moura, G. L. (2005). Relações de conhecimento consultor organizacional- cliente à luz da biologia do conhecer: uma reinterpretação para desfazer mal-entendidos correntes. Dissertação de mestrado, Universidade Federal de Pernambuco (UFPE), Recife, PE, Brasil.

Neves Jr, L. T., Jr. (2002). Consultoria! O que é e como usar. Recuperado em 26 maio, 2018, de http://www.sebrae-sc.com.br/newart/?materia=4006

Oliveira, D. P. R. (2009). Manual de consultoria empresarial: conceito, metodologias e práticas (8a ed.). São Paulo: Atlas.

Oliveira, E. S. (2005). Critérios de decisão relevantes na escolha e contratação de serviços de consultoria de gestão: a perspectiva dos clientes. Dissertação de Mestrado, Faculdade de Economia, Administração e Contabilidade, Universidade de São Paulo, São Paulo, Brasil.

Oliveira, R. V. (2011). O polo de confecções do agreste de Pernambuco: ensaiando uma perspectiva abordagem. In Anais do Encontro Anual da Anpocs, XXV, Caxambu, MG, Brasil, 35.

Oliveira, R. V. (2013). O Polo de Confecções do Agreste de Pernambuco: elementos para uma visão panorâmica. In Oliveira, R. V., \& Santana, M. A. (Orgs.). Trabalho em territórios produtivos reconfigurados no Brasil. João Pessoa: Editora da UFPB.

Oliveira, R. V., \& Braga, B. M. (2014). Território comercial de Toritama: persistência e metamorfoses da informalidade. Revista de Ciências Sociais - Políticas \& Trabalho, 2(41), 193-225.

Padula, A. D., \& Vadon, J. (1996). Uma metodologia de diagnóstico organizacional global para a consultoria de gestão em pequenas e médias empresas. Revista de Administração, 31(1), 32-43.

Pereira, A. M. B. A. (2018). Dinâmica formal-informal em lavanderias de jeans e suas implicações nas relações de trabalho. Tese de doutorado, Universidade Federal de Campina Grande (UFCG), Programa de Pós-graduação em Administração (PPGA), João Pessoa, PB, Brasil.

Pereira, E. (2011). Qualificação profissional e relações de trabalho no polo de confecção de Pernambuco: trajetória e perspectivas de atuação do SENAI. Dissertação de mestrado, Universidade Federal de Campina Grande (UFCG), Campina Grande, PB, Brasil.

Pereira, E., \& Oliveira, R. V. (2013). Modos de atuação do SENAI no Polo de Confecções de Pernambuco: mudanças recentes e implicações recíprocas. In Oliveira, R. V., \& Santana, M. A. (Orgs.). Trabalho em territórios produtivos reconfigurados no Brasil. João Pessoa: Editora da UFPB.

Pereira, J. (2013). O programa empreendedor individual e as estratégias de formalização das atividades econômicas do Polo de Confecções do Agreste Pernambucano. In Oliveira, R. V., \& Santana, M.A (Orgs.). Trabalho em territórios produtivos reconfigurados no Brasil. João Pessoa: Editora da UFPB.

Sá, M. G. (2015). Os filhos das feiras e o campo de negócios agreste. Tese de doutorado, Universidade do Minho, Instituto de Ciências Sociais, Braga, Portugal.

Santos, A. L., Krein, J. D., \& Calixtre, A. B. (2012). Micro e pequenas empresas: mercado de trabalho e implicação para o desenvolvimento. Recuperando em 27 maio, 2018, de http://repositorio.ipea.gov.br/bitstream/11058/3006/1/Livro_Micro\%20e\%20pequenas\%20empresas\%20 mercado\%20de\%20trabalho\%20e\%20implica\%C3\%A7\%C3\%A3o\%20para\%20o\%20desenvolvimento.p df.

Schein, E. H. (1972). Consultoria de procedimentos: Seu papel no desenvolvimento organizacional. São Paulo: Edgard Blücher.

Schmidt Neto, A. (2004). A importância da consultoria na implantação de sistemas ERP: Um enfoque em médias empresas industriais do Vale do Itajaí e Norte de Santa Catarina. Revista Administração, Contabilidade e Economia, 3(1), 31-44. 
SEBRAE [SEBRAE] (2014). Participação das micro e pequenas empresas na economia brasileira. Recuperado em 20 maio,2018, de http://www.sebrae.com.br/Sebrae/Portal\%20Sebrae/Anexos/Estudo\%20Economico\%20do\%20APL\%20d e\%20Confeccoes\%20do\%20Agreste\%20-\%20\%2007\%20de\%20MAIO\%202013\%20\%20docx.pdf.

Serviço Brasileiro de Apoio às Micro e Pequenas Empresas [SEBRAE] (2013). Estudo econômico do Arranjo Produtivo Local de Confecções do Agreste Pernambucano. Recuperado em 20 maio, 2018, de http://www.sebrae.com.br/Sebrae/Portal\%20Sebrae/Anexos/Estudo\%20Economico\%20do\%20APL\%20d e\%20Confeccoes\%20do\%20Agreste\%20-\%20\%2007\%20de\%20MAIO\%202013\%20\%20docx.pdf.

Silva, A. S. (2009). Qual o papel do cliente, quando contratação do serviço de consultoria, para a geração do seu próprio aprendizado. Anais do Encontro da Associação Nacional de Pós- Graduação e Pesquisa em Administração, XXXIII São Paulo, SP, Brasil

Silva, F. F., Ribeiro, A. R. B., \& Silva, W. F. (2018). Consultoria Organizacional como um Instrumento de Inovação em Arranjos Produtivos Locais. Revista Organizações em Contexto, 14(27), 29-52.

Silveira, F. Z. (2007). Massificação da consultoria: descrição e análise dos processos de mudança do Sebrae-SP. Dissertação de mestrado, Departamento de Engenharia de Produção da Universidade Federal de São Carlos (UFSCar), São Carlos, SP, Brasil.

Teixeira, G. C. (2012). Referenciais de consultoria do SEBRAE. Recuperado em 24 maio, 2018, de http://www.bibliotecas.sebrae.com.br/chronus/ARQUIVOS_CHRONUS/bds/bds.nsf/C08A566FFBE7EE 29832579CF0049C370/\$File/NT000474F2.pdf.

Vergara, S. C. (2009). Projetos e relatórios de pesquisa em administração (10a ed.). São Paulo: Atlas.

Wood Jr., T., \& Caldas, M. P. (2005). Rindo do quê? Como consultores reagem ao humor crítico e à ironia sobre sua profissão. Revista Organizações \& Sociedade, 12(34),83-111.

Zanatta, M. S. (2016). Quando o fabrico se torna fábrica: desdobramentos do processo de formalização dos empreendimentos industriais de confecções em Caruaru/PE. Tese de doutorado, Universidade Federal do Rio Grande do Sul (UFRGS), Instituto de Filosofia e Ciências Humanas, Programa de Pós-Graduação em Sociologia, Porto Alegre, RS, Brasil.

\title{
The practice of Consulting in the Informal Dynamics of the clothing pole from the "Agreste Pernambucano"
}

\begin{abstract}
The present work sought to characterize the phases of intervention in consultants's action and their perceptions on informality of the socioproductive experience of the clothing pole from the "Agreste Pernambucano". To achieve this objective, a qualitative research was carried out using interviews with consultants working in the segment. A theoretical framework was used, contemplating the theme of consulting and the history of the clothing pole, its constitutive dynamics and recent transformations. The results of this research indicate that in the intervention stages adopted by the consultants, there are variations between the approaches and a sequence of logical phases is adopted, which will, in principle, guide the agents' performance with the client systems, but with an openness to adjustments to reality of companies. As for the informality, the consultants were faced with family companies immersed in traditional forms of organization, intuitive management, lack of planning, parallel to practices referred to the formal standard, resulting in the hybridism between the traditional and the modern.
\end{abstract}

Keywords: Consulting, Informality, The clothing pole from the "Agreste Pernambucano”. 


\title{
La práctica de la Consultoría en la Dinámica Informal del Polo de Confecciones del Agreste Pernambucano
}

\begin{abstract}
Resumen
El presente trabajo buscó caracterizar las fases de intervención en la acción de los consultores y sus percepciones sobre la informalidad en la experiencia socioproductiva del Polo de Confecciones del Agreste Pernambucano. Para alcanzar ese objetivo se realizó una investigación de carácter cualitativo utilizando entrevistas junto a consultores actuantes en el segmento. Se hizo uso de un marco teórico, contemplando la temática de la consultoría y la historia del Polo de Confecciones, en su dinámica constitutiva y en las transformaciones recientes. Los resultados de esta investigación indican que en las etapas de intervención adoptadas por los consultores hay variaciones entre los enfoques y se adopta una secuencia de fases lógicas que, en principio, guirán la actuación de esos agentes junto a los sistemas clientes, habiendo apertura para ajustes a la realidad de las empresas. En cuanto a la informalidad, los consultores se encontraron con empresas familiares inmersas en formas de organización tradicionales, gestión intuitiva, ausencia de planificación y en paralelo, con prácticas referidas al estándar formal, resultando un híbrido entre lo tradicional y lo moderno.
\end{abstract}

Palabras Clave: Consultoría, Informalidad, Polo de Confecciones del Agreste Pernambucano..

\section{Sobre os Autores}

\section{Amanda Lima VASCONCELOS}

Graduada em Administração pela Universidade Federal de Pernambuco (UFPE)

Rodovia BR-104, Km 59, s/n - Nova Caruaru - Caruaru - PE - Brasil - CEP 55002-970.

E-mail: amandalima.v@hotmail.com

\section{Ana Márcia Batista Almeida PEREIRA}

Professora do curso de Administração da Universidade Federal de Pernambuco (UFPE), Centro Acadêmico do Agreste (CAA). Doutora em Administração, Pesquisadora do GEIA (Grupo de Estudos e Intervenções do Agreste/UFPE) e TDEPP (Grupo Trabalho, Desenvolvimento e Políticas Públicas/UFCG).

Rodovia BR-104, Km 59, s/n - Nova Caruaru - Caruaru - PE - Brasil - CEP 55002-970.

E-mail: anabatistaalmeida@gmail.com 